\title{
The SpaceX Effect
}

Vidya Sagar Reddy

Nuclear and Space Policy Initiative, Observer Research

Foundation, New Delhi, India.

\begin{abstract}
Space Exploration Technologies Corporation (SpaceX) had demonstrated its reusable launch vehicle technology by recovering and reusing the core stage of its Falcon 9 launch vehicles. SpaceX believes reusable launch vehicles will enable its vision of colonizing Mars. This had unleashed pricing competition as SpaceX had begun offering low-cost access to space. Rival launch service providers, although contentious of SpaceX business model, are planning to introduce reusable launch systems into their product mix. This article offers a survey of such launch service providers from 4 distinct geographical regions with varying degrees of public-to-private ownership and catering to different requirements. The study conveys that regardless of these variables, reusability is fast becoming the norm of the launch vehicle industry. Interestingly, managers of these programs do not shy from admitting that Elon Musk and SpaceX are influential factors in their decision-making. The article argues that the space industry is witnessing a major disruption guided by innovation and determination to take bold risks. The core argument is that even though SpaceX is yet to prove its business model, perhaps the real effect of it is not in making profits but in leading a permanent change in the space industry.
\end{abstract}

Keywords: SpaceX, Arianespace, United Launch Alliance, reusable launch vehicles, innovation, disruption, low-cost price competition, launch cadence, reuse, business model

\section{INTRODUCTION}

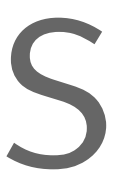

pace Exploration Technologies Corporation (SpaceX) has made history in March 2017 by successfully relaunching the core stage of a rocket initially flown a year before. Although the concept of reusable launch vehicles itself is not new as the American space shuttle program has proven, this is the first time in space history for a commercial launch vehicle company to attempt this feat. Commercial satellite companies have welcomed the initiative hoping to launch their satellites at low cost. Even as the space industry is debating the viability of SpaceX business model, government and commercial launch vehicle operators across the world are compelled to alter their traditional thinking on launch vehicles. The United Launch Alliance (ULA), Arianespace, Indian Space Research Organization (ISRO), and China's launch vehicles executives are now planning to introduce this concept to stay competitive in the pricing war. Managers of these programs continue to refer to Elon Musk and SpaceX in taking decisions. Therefore, more than profit margins, SpaceX should be identified with the disruption it is leading in the global space industry.

\section{MARS, AIRPLANES, AND REUSABLE LAUNCH VEHICLES}

In the traditional scenario, a satellite launch vehicle is expendable. The core stage and accompanying boosters are discarded in the ocean, whereas the upper stage is left orbiting the Earth. Past attempts to retrieve and reuse launch vehicles have failed due to the lack of a better combination of technology and viable business model. The United States had designed space shuttles for transporting cargo and astronauts to the International Space Station (ISS). The space shuttle is in essence a spaceplane launched into orbit using 2 solid rocket boosters and an external fuel tank feeding the shuttle's engines. The shuttle would re-enter the atmosphere and land on a runway akin to an airplane that would thereafter undergo refurbishment and relaunched. The 2 solid rocket boosters ejected after a few minutes into the flight are retrieved and refurbished for next mission. The external tank is the main component that is left to disintegrate during re-entry. The shuttle was designed to keep the cost of access to space low by flying at least 50 times a year with an average cost of $\$ 450$ million per launch. ${ }^{1}$ However, refurbishment process and actual flight rate of only 4 per year bloated the cost into billions. The calculations show that the average cost per shuttle launch is about $\$ 1.2$ billion during the operational years from 1982 to 2010 , which increases to $\$ 1.5$ billion over the life of the shuttle program. ${ }^{2}$

Michael Griffin, former Administrator of National Aeronautics and Space Administration (NASA), agrees with the opinion that the U.S. human spaceflight program took a wrong direction by terminating Apollo and embarking on the ISS and space shuttle projects. ${ }^{3}$ The United States had terminated the space shuttle program in 2011 with the expectation that commercial launch vehicle operators would offer that capability by 2015. However, Orbital ATK and SpaceX are 
currently carrying cargo to the ISS but the commercial crew program contracts awarded to Boeing and SpaceX may not materialize before 2019. ${ }^{4}$ This situation had led to the Russian spacecraft Soyuz gaining monopoly on crew transportation to the ISS. With its position firming up, Russia intends to charge the United States $\$ 81$ million per seat in 2018 against only $\$ 22$ million in 2008, a cost increase of $370 \%$ over 10 years. ${ }^{5}$ NASA expects that the commercial crew program would result in a per seat cost of approximately $\$ 58$ million. ${ }^{6}$ In addition to reducing the cost of crew transportation to the ISS, SpaceX, led by Elon Musk, is confident that it will enable low-cost transportation to Mars. ${ }^{7}$

The aim of SpaceX in pursuing Mars is to make humanity a multiplanetary species. Musk perceives that innovative manufacturing and management of airplanes started a revolution in the transportation sector, enabling businesses and advancing a new industrial ecosystem. The airline industry manufactures planes that can be reused multiple times with minimal checkouts and fast refueling between the flights. Much like Pan Am and other commercial aviation companies that have revolutionized transatlantic flight during the 20th century, SpaceX is aiming to transform human and cargo transport between Earth and Mars. As a result, the company started designing a launch vehicle with reusability in mind. ${ }^{8}$ Musk believes that robust engineering practices and simplified business model would allow SpaceX to reduce the turnaround time and refurbishment cost of his launch vehicle. In essence, SpaceX intends to succeed where NASA had failed.

\section{MODEL ENGINEERING AND MODEST COST}

SpaceX is upgrading the Dragon spacecraft it currently uses for transporting cargo to the ISS for human missions. The company is confident that commonality of systems and reusability will lower the cost of space transportation. Its Falcon 9 launch vehicle uses the same Merlin engines for both the stages ( 9 for the core stage and 1 for the second stage) and high strength aluminum-lithium alloy for manufacturing. ${ }^{9}$ The Falcon Heavy launch vehicle derives its power and reliability by adding 2 additional core stages as boosters to an individual Falcon 9. Both the boosters on first Falcon Heavy will be previously flown Falcon 9 core stages but with a new center module. ${ }^{10}$ The future Interplanetary Transport System to be used for transportation to Mars will build on this heritage. The company makes it an economic principle to adopt flightproven hardware and commonality in design to reduce risk and expedite development of new launch vehicles. It also manufactures most of the components in-house to ensure timely delivery and keep the cost of production low. ${ }^{11}$ However, the most significant technological step for SpaceX en- abling its vision to offer cheaper space transportation options is the successful vertical landing of Falcon 9 core stage.

Musk hinted at making the Falcon 9 fully reusable in 2009 and started experimenting with Grasshopper and Falcon 9 Reusable (F9R) test vehicles between 2012 and 2014. ${ }^{12}$ Grasshopper is a Falcon 9 core stage with a single engine that used steel landing legs. F9R consisted of 3 engines and used steerable grid fins. These test flights demonstrated vertical take-off, lateral maneuvers, and pinpoint vertical landing. The critical moment arrived in March 2017 when SpaceX had launched and successfully landed a reused Falcon 9 core stage that was initially flown in April 2016 carrying cargo to the ISS. ${ }^{13}$ Musk termed the event a "huge revolution" in spaceflight that will bring down the cost of space transportation. Societe Europeenne des Satellites (SES), owner of the satellite flown on reused rocket, had confirmed that it received a discount on the launch cost but declined to reveal the exact figure. ${ }^{13}$ As of October 2017, SpaceX had successfully recovered the core stage 18 times out of 23 attempts with the latest recovery being the 14 th success in a row. ${ }^{14}$ SpaceX is planning to also retrieve and reuse the Falcon 9 upper stage, its payload fairings, and the Dragon spacecraft to make the system fully reusable, further lowering the costs. Musk believes that there is potential for $>100$-fold reduction in the cost of access to space if turnaround can be reduced to mere $24 \mathrm{~h} .{ }^{15}$ It means, like an airplane, SpaceX needs to keep the time and cost of refurbishment low in this process.

Gwynne Shotwell, SpaceX President, had commented that the refurbishment cost of the reused Falcon 9 core stage in March 2017 was lower than half the cost of a new stage. ${ }^{16}$ SpaceX puts the cost of its core stage at 70\% of the total launch cost ( $\$ 61.2$ million), which comes to $\$ 18.3$ million while fueling costs between $\$ 0.2$ and $\$ 0.3$ million. ${ }^{17}$ Therefore, the refurbishment cost of this core stage is $<\$ 9.15$ million, and adding the maximum fueling cost, the reused core stage costed $\sim \$ 9.45$ million. Shotwell says that SpaceX engineers will eventually reduce the refurbishment work to only one-tenth required for the March 2017 core stage. ${ }^{18}$ Ultimately, the rocket should be able to fly 10 times with no hardware changes and at least a 100 times with moderate refurbishment done within $24 \mathrm{~h}$. Over a minimum cadence, SpaceX is offering $30 \%$ reduction on the current price of Falcon 9, making it available for $\$ 42.8$ million. The cost could be further reduced to $\$ 37$ million if the company transfers $100 \%$ of the cost savings to its customers. ${ }^{19}$

\section{ENTER THE FALCON}

The ULA, a joint venture between Lockheed Martin and Boeing, used to enjoy monopoly in the U.S. commercial launch 
vehicle market. Its main customers are Department of Defense and intelligence community which are concerned about the reliability of launch vehicles than cost. The profit margin built into the cost of ULA's launch vehicles has to be overlooked even by other departments such as NASA given the monopoly. But the ULA launch prices are so exorbitant that the U.S. Air Force (USAF) estimates the maximum unit cost of a single rocket launch in fiscal year 2020 is $\$ 422$ million. ${ }^{20}$ This is where SpaceX had found its market. It had gained NASA's development awards and contracts helping it refine the hardware and manufacturing processes. Meanwhile, SpaceX had accused the USAF of deliberately delaying the certification of its launch vehicle for national security space missions and went on to file a lawsuit. ${ }^{21}$

The USAF finally certified SpaceX in 2015 allowing it to win second GPS III satellite launch contract in 2016 without any competition. ULA had commented that the restrictions imposed by the U.S. Congress on Russian engines used by Atlas V made it difficult to bid for the contract. However, according to a recently fired executive of ULA, the company had abstained from bidding because of the competitive pricing offered by SpaceX. ${ }^{22}$ The executive went on to allege that Musk had engineered the ban on Russian engines as part of the U.S. sanctions on Russia after the Ukraine crisis. Later, these firms competed for launching the third satellite in the GPS III series, with SpaceX winning the contract. If SpaceX could firm up its low-cost launches, then it could possibly outbid ULA winning national security missions on bulk as the exchequer is under financial sequestration.

\section{CRITICISM AND EVENTUAL TURNAROUND}

ULA had played its "reliability" card against SpaceX's "lowcost" option for winning the launch contracts. However, with SpaceX steadily improving its reliability matrix in addition to offering low-cost launches based on the reusability mechanism, ULA also had set out to examine the cost benefit and possibly adopt the concept. Its chief executive had played down reusable rockets saying that they could offer utmost $10 \%$ cost savings. ${ }^{23}$ His analysis finds it difficult to accumulate more savings with the procedure SpaceX had adoptedretrieving and refurbishing the entire core stage. Moreover, Falcon 9 operates at reduced performance due to the extra weight of landing legs, steerable fins, and reserve fuel for descent maneuvers. The potential impact of retrieving the upper stage is found to be significant, resulting in a poundfor-pound performance penalty. ${ }^{18}$

Therefore, ULA has come up with a new rocket design that adopts reusability without degrading the performance of the rocket. This design will also avoid costly refurbishment. The
Vulcan will debut in 2019 whereupon the company will also terminate its reliance on Russian engines. Vulcan will combine the best design features of Atlas V and Delta IV with launch capability exceeding that of Delta IV Heavy, making it reliable for national security launches. Vulcan will be powered by either Blue Origin's methane-fueled BE-4 engine or Aerojet Rocketdyne's kerosene-fueled AR1 engine. The U.S.-made engines will bring stability to ULA production lines that are disrupted by geopolitics. The company expects the price to drop down to $\$ 100$ million at the base level for Vulcan from $\$ 160$ million demanded for an Atlas $\mathrm{V}^{24}$

It is also planning to make some parts of the rocket reusable starting in 2024. Instead of recovering the entire core stage, ULA is planning to recover and reuse only Vulcan's engines under the Sensible, Modular, Autonomous Return Technology (SMART) initiative. The engines will be desegregated from the stage, decelerated and recovered in midair using helicopters. ULA had assessed that it makes economic sense to recover the engines that weigh only a quarter of the core stage's overall weight but costs $65 \%$ of the stage's entire cost. ${ }^{25}$ Therefore, this process keeps the performance of the rocket steady while allowing the company to recover only the valuable components on a rocket stage. The refurbishment and certification mechanisms employed in this process would be swift and less costly. ULA concedes that reusability is not about complex technological mechanisms but about the pure economics of it. ${ }^{26}$ According to ULA, the minimum launch cadence needed to breakeven using SpaceX mechanism is about 10 while it can do with only 2 launches. ${ }^{27}$

\section{INTERNATIONAL RESPONSES}

SpaceX is changing the equations of traditional launch vehicle operators even outside the United States. Arianespace is a French multinational company primarily catering to European launch requirements. It offers Ariane 5, Soyuz (Europeanized), and Vega rockets launched from Europe's spaceport in French Guyana. It is the world's first commercial launch service provider with Ariane 5 recording $>79$ successful launches in a row. ${ }^{28}$ The company orbited $>50 \%$ of the world's telecommunications satellites to date. Although the solid rocket boosters on Ariane 5 have been retrieved occasionally using parachutes for postflight analysis, reusing them is considered to be economically ineffective. ${ }^{29}$ However, one study had concluded that reusing the core stage of the vehicle could save $\$ 8.5$ million per flight. ${ }^{30}$ Ariane 5 currently costs \$165-220 million on the international market and a reduction of $\$ 8.5$ million on this price does not make it competitive enough with NewSpace entities such as SpaceX. ${ }^{31}$ 
A competition between Arianespace and SpaceX is expected on the international market with Russian Proton experiencing frequent launch failures. A commercial satellite operator Inmarsat switched its satellite from SpaceX to Arianespace recently owing to the delay in Falcon Heavy launch. It took this step to conform to the regulatory deadlines rather than a signal of competition. ${ }^{32}$ However, SpaceX and reusability are discussed in the European space market and they emerge as major factors in decisions about the future of Arianespace. Approving the Airbus Safran Launchers takeover of Arianespace, the European Commission had noted SpaceX's achievements while commenting that the international launch market has become highly dynamic, allowing the customers some buying power. ${ }^{33}$ However, Arianespace is not rushing to alter the formula that has given it consistent results for adopting reusability. It will continue launching the current, proven Ariane 5 configuration that has established a track record. ${ }^{34}$

The French space agency had estimated that a completely reusable core stage booster would have to fly at least 50 times a year to lower the cost by $10 \%-20 \%$, whereas Arianespace chief executive Stephane Israel puts the number between 35 and 40 launches. ${ }^{35}$ Another official doubts the stage or boosters retaining their initial performance and reliability for a fourth or fifth launch even as others question SpaceX wisdom due to its noncompliance with mass production principles. ${ }^{36}$ The core argument here is the minimum launch cadence required for seeing considerable cost savings that can be distributed to the customers. Israel argues that such a cadence may not be possible even in high-density markets such as the United States or China and it is certainly beyond the scope of Europe. Therefore, SpaceX could become aggressive on the international launch market, threatening Arianespace market share.

Even as Arianespace moves ahead with restructuring plans cutting jobs, the long-term plan to survive the price competition has resulted in a new launch vehicle design Ariane 6. It will still be an expendable launch vehicle, but the company expects to reduce the production costs by innovating on existing components and trimming assembly lines. Ariane 6 engines will be built with fewer parts but increased efficiency. In addition, the solid motor boosters on Ariane 6 will also power upgraded Vega $C$ rocket, increasing booster production rate to 35 per year. Arianespace will also update rocket integration mechanism moving it closer to the launch site. The company expects to reduce the overall cost of maintaining the current production line by $40 \%-50 \%$. Ariane 6 is expected to debut in 2020 flying at least 11 times a year with an average cost of \$90-100 million. ${ }^{34}$ It will relieve the European gov- ernments from securing $€ 20$ million required for covering the difference between Ariane 5 production and selling costs. ${ }^{36}$ Therefore, Arianespace's path to reducing the cost of access to space is lightening the production costs and improving the efficiency of systems already in place.

Nevertheless, Arianespace does not rule out utilizing reusable systems. The French space agency had collaborated with Russia on the Baikal reusable launch vehicle program that did not materialize. In 2015, the space agency had started collaboration with an aerospace research firm to design a reusable first stage. These projects are concerned with retrieving the entire core stage akin to SpaceX. However, Airbus, a prime contractor for Arianespace, is taking the approach preferred by ULA. It is working on Advanced Expendable Launcher with Innovative engine Economy (Adeline) concept wherein only the valuable components such as the engine and avionics will be retrieved and reused. Adeline can be adapted to any launch vehicle in the future such as Ariane 6 around 2025.

Adeline differs from ULA's SMART concept in that the Adeline module will reenter the atmosphere and glides to a runway using wings and propellers. Airbus is relying on flight-proven unmanned aerial vehicle technologies to realize this concept. Adeline will be protected by a heat shield throughout the process, allowing the company to reduce the turnaround time. The performance penalty on the launch vehicle because of the extra weight of wings, propellers, and reserve fuel is expected to be less than that of Falcon 9. Airbus believes that Ariane 6 needs to add only 2,000 kg of extra fuel to launch with and return Adeline, whereas SpaceX needs to add at least $35,000 \mathrm{~kg}$ of extra fuel for returning the core stage. ${ }^{37}$ Adeline can be reused 10-20 times and will help offset $20 \%-30 \%$ of flight cost, which can be increased to $50 \%$ with better streamlining of the process. ${ }^{38}$ Work on Adeline is in conceptual and initial design phase making it hard to calculate the percentage of cost savings and minimum launch cadence essential for breaking even.

Similarly, Airbus Safran Launchers will be working on European Space Agency funded Prometheus project for realizing a reusable rocket engine. This liquid oxygen and methane-fueled engine will be ready for test firing in 2020 and is expected to enter into service by 2030 . The engine is estimated to cost only $\$ 1.1$ million, one-tenth the cost of Vulcain 2 engine used in the first stage of Ariane $5 .{ }^{39}$ Threedimensional printing, predictive maintenance, and digital control technologies will be incorporated to keep the cost of engine manufacturing low. Adeline proposes to bring back the engine on Ariane vehicles for reuse and Prometheus could fit into this concept as both projects evolve. The commissioning of these projects signals innovation and a change in 
the mindset of Arianespace, leading to low-cost launches to space.

\section{FOLLOWING ON TO AN ARIANESPACE CUSTOMER}

Moreover, Arianespace is committed to flying Vega and Soyuz launch vehicles tapping into different satellite industries, particularly small satellites. SpaceX does not consider small satellites as its primary market and had discontinued flying Falcon 1 launch vehicle. ${ }^{40}$ However, major space and nonspace companies such as Planet, OneWeb, Google, and Facebook now deem outer space as the common medium for expanding their services into emerging markets in Asia and Africa. These companies plan to orbit thousands of small satellites in low Earth orbit (LEO) for providing messaging, internet, imagery, and surveillance services for a broad range of customers. OneWeb is planning to place $>2,000$ satellites in LEO for providing satellite internet. ${ }^{41}$ It has booked 21 launches of Arianespace Soyuz costing upwards of $\$ 1$ billion, making it the world's largest commercial launch contract. ${ }^{42}$ Facebook's plan to open Internet.org over Africa was disrupted because of the explosion of Falcon 9 recently. SpaceX is also trying to enter into this market by designing a network of 4,425 internet satellites that will be launched using Falcon 9 starting in $2019 .{ }^{43}$ Arianespace will debut upgraded Vega C in 2018 that will carry the same core stage motor as the boosters on Ariane 6. Perhaps Adeline concept could also be adapted to Vega $\mathrm{C}$, thus trimming its production costs. The cost savings from adopting commonality and reusable mechanism across its launch vehicles can help Arianespace sustain capital inflow and stand out in the competition with SpaceX.

Even as Arianespace competes with SpaceX primarily for geostationary launches, its competition in the LEO might be arising from one of its own customers-India. India has recently placed 104 satellites into this orbit in a single launch creating a world record. Of these, 96 are small satellites from the U.S.-based commercial Earth imaging companies Planet and Spire Global. ${ }^{44}$ These 2 companies have flown previously onboard India's Polar Satellite Launch Vehicle (PSLV) despite restrictions by the U.S. government. The United States contends that the PSLV cost is subsidized by India making it distort free market principles. ${ }^{45}$ These restrictions are set in place until India and the United States resolve this issue and conclude a Commercial Space Launch Agreement. Over the years, the United States had concluded such agreements with Russia, Ukraine, and China.

However, U.S. commercial small satellite companies could obtain a waiver from the U.S. government to launch on PSLV. This emerging industry is interested in PSLV because of its reliability and cost competitiveness. As of June 2017, the
PSLV had flown 39 consecutively successful missions carrying 48 Indian and 209 foreign satellites into orbit. ${ }^{46}$ Its maximum capacity is $1,750 \mathrm{~kg}$ to a $600 \mathrm{~km}$ polar orbit with an average cost of $\$ 15$ million. ${ }^{47}$ It had also proven its capability to inject multiple satellites into multiple orbits. These parameters compel the U.S. small satellite operators to lobby Washington DC to remove the restrictions on PSLV even as the Federal Aviation Administration's Commercial Space Transportation Advisory Committee had recommended continuing the ban. ${ }^{48}$ The committee is concerned that removing the ban on India's PSLV could diminish the prospects of creating a domestic small satellite launch industry.

\section{FROM COMPETITION TO POTENTIAL PARTNERSHIP}

Counting on the international market, India is taking steps to increase its launch frequency to 12 per year. It has operationalized the Geosynchronous Launch Vehicle (GSLV) Mk II and successfully debuted the Mk III version recently enabling it to launch $4,000 \mathrm{~kg}$ into the geostationary orbit. India is so far reliant on Arianespace for launching its communications satellites, which is expected to continue although at a reduced pace because of the satellites becoming heavier. GSLV Mk III will take 1 or 2 more developmental flights to become operational, meaning the majority of these 12 launches will be of PSLV. At least 2 of these launches will be dedicated to commercial missions owing to increasing global interest in small satellites. Antrix, the commercial arm of ISRO, makes nearly $\$ 3$ billion out of its $\$ 20$ billion turnover from launching PSLV missions for foreign satellite operators. ${ }^{49}$ It already has a backlog of orders worth $\$ 6$ billion. ISR0 is formulating the ground rules for establishing a joint venture with the private industry to commercialize the PSLV. It is expected to bring transparency in cost and offload the production burden to the industry, making the vehicle more competitive on the international launch market. It is also adding a new vehicle assembly building and a launch pad to increase the launch cadence.

ISRO expects to eventually handover the routine production and integration jobs to the industry and focus on technology development activities such as reusable launch vehicles. It has initiated the reusable launch vehicle technology demonstrator (RLV-TD) program as a test bed to evaluate critical systems for realizing completely reusable 2 -stage to orbit launch vehicle. ${ }^{50}$ RLV-TD looks like a mini space shuttle with a nose cap, fuselage, delta wings, and vertical tails along with elevons and rudders to control the structure during the flight. The hypersonic experiment conducted in 2016 validated a reusable thermal protection system, autonomous navigation, 
guidance and control, and re-entry mission management. Future experiments will validate hypersonic flight using air breathing propulsion, re-entry, and autonomous landing technologies. Eventually, improved and fully tested RLV-TD will become the core stage of ISRO's 2-stage to orbit launch vehicle. $^{51}$

The mechanism for retrieving the second stage of this vehicle is currently unknown. The final version of India's reusable launch vehicle will take at least 10-15 years to materialize. Whether these experiments will yield a completely new vehicle or will ISRO adopt reusable technology features to its expendable launch vehicles remains to be seen. It could try retrieving and reusing core stage components on GSLV to make them more cost-effective..$^{52}$ Currently, the organization is collecting data on hypersonic flight regime, building robust avionics modules, sophisticated communications and guidance systems, re-entry, and autonomous landing technologies. ${ }^{53}$ The winged design and runway landing could help reduce retrieval and refurbishment processes akin to Adeline. ISRO contends that RLV-TD is an open architecture program to evaluate various technological options to retrieve and reuse launch vehicles or components. It will be studying SpaceX, ULA, and Arianespace concepts and evaluate future space industry scenario to settle on an optimum design. However, the stated economical aim is to reduce the cost of access to space from $\$ 10,000$ to $\$ 2000$ per $\mathrm{kg}$ with which India could retain its competitive edge on the international launch market. $^{54}$

However, India and France do not foresee themselves as competitors. On the contrary, they envision collaboration as the French space agency has formed a working group with ISRO to study reusable launch technologies. ${ }^{55}$ France and India enjoy decades of close cooperation in space, particularly on launch vehicle technologies. A joint effort will help both the sides stay competitive on the international launch market, which is witnessing pressure from the U.S. commercial launch companies in reaching both LEO (Vector Space Systems, Virgin Orbit, and Rocket Lab) and geostationary orbits (SpaceX), and perhaps even China.

\section{ENTER THE DRAGON}

India is not the only Asian space power interested in reusable launch vehicle technologies. Its geopolitical peer China is also testing key technologies for this purpose. Even as Indian and Chinese space achievements are contrasted within the Asian space race narrative, China is emerging a bigger competitor on the international launch market. It had figured briefly on this market in the 1990s, winning launch contracts from the U.S. commercial satellite manufacturers such as
Hughes. However, this cooperation had faltered because of frequent Long March rocket failures and the imposition of sanctions on China for diverting launch vehicle technology for missile production and human rights violations. Nevertheless, the China Great Wall Industry Corporation that promotes China's commercial satellite manufacturing and launch services across the world has found an emerging market in the Global South. It had won contracts from Nigeria, Bolivia, Venezuela, Pakistan, Sri Lanka, and Laos for building and launching their communications and remote sensing satellites. ${ }^{56}$ China now competes with the United States and Russia for the most number of launches in a year. China and the United States launched 22 times in 2016 tying for the first spot, with the former planning to attempt 30 launches in 2017. Although majority of these launches will be for domestic purposes, China also has unveiled low-cost commercial launch services.

Its Kuaizhou-1A launch vehicle can carry $200 \mathrm{~kg}$ payload into a $700 \mathrm{~km}$ LEO. It has placed 3 satellites into orbit on its first commercial mission in January $2017 .{ }^{57}$ In addition, it is developing Naga-L with the capability to place $600 \mathrm{~kg}$ into $800 \mathrm{~km}$ polar orbit for $\$ 10$ million. ${ }^{58}$ China is negotiating with Indonesia, Tanzania, and Sweden to host launch sites for Naga-L to circumvent U.S. restrictions on exporting satellite components to China. It is also promoting companies such as Landspace, OneSpace, and ExPace to market small satellite commercial launch services to Europe, South East Asia, etc. Alongside promoting commercial small satellite launchers, China's 2016 white paper on space activities also call for researching reusable space transportation systems for lowering the cost of access to space. ${ }^{59}$ China Aerospace Science and Technology Corporation followed up the white paper by revealing a reusable rocket engine design that can be used 50 times. ${ }^{60}$ China Academy of Launch Vehicle Technology through its commercial subsidiary is also working on reusable suborbital launch vehicle to be debuted in $5-10$ years. ${ }^{61}$

China also has made some preliminary experiments on vertical landing system such as SpaceX and parachute-airbag system before deciding to proceed further with the latter option. The parachute-airbag system slows down the rocket stage whereas the airbag provides cushion against hard landing at a predesignated recovery zone. ${ }^{62}$ Experts criticized this approach because of the risk from geographical and environmental factors. The final decision on this design is expected sometime in 2020. China's military in contrast is developing the Shenlong spaceplane that resembles the American X-37B military spaceplane. ${ }^{63}$ Given the fact that China does not maintain a distinction between the civilian and 
military aspects of its space program, Shenlong could be adopted for future reusable launch vehicle requirements.

\section{THE SPACEX EFFECT: IMPOSSIBLE TO ACCEPTANCE}

Human history is replete with the stories of men journeying to distant parts of the world compelled by their natural quest for exploration. One of these journeys in search of the New World eventually led to the foundation of the United States. It has since become home to generations of entrepreneurs such as Ford and Hughes, who have disrupted traditional modes of thinking with their inventions and business models. Continuing this tradition is the next generation taking bold risks in their quest to settle the final frontier. Elon Musk believes in making humanity multiplanetary for better survival of the species. His quest to settle on Mars requires independent, cheaper, and frequent access to space. Musk's team had approached the Russian launch vehicle designers for landing a preliminary experiment on Mars. Apparently, the team was mistreated driving Musk to build his own rocket. ${ }^{64}$ This story possesses a critical element that has come to define the success of inventors, scientists, and entrepreneurs across the world. There were instances wherein critical inventions and business models that have come to define the modern world were initially criticized to be sure failures. Musk's vision of reusable launch vehicles, which goes against the traditional approach of expending the rockets, is one such innovation.

Reusable launch vehicles struggled to become a norm because of the early demise of Russian Buran and the escalated cost of U.S. space shuttle. Dan Dumbacher, former Head of Engineering Directorate at NASA's Marshall Space Flight Center, argues against reusable launch vehicles based on the shuttle experience. His argument is that maintaining reusable rockets is fundamentally different to running airplanes because of divergent operational environments. ${ }^{65}$ However, his pessimism seems to extend to a point of underestimating human ingenuity. Musk's intention is to alter this perception by demonstrating that reusable launch vehicles could be made cost-effective with innovation. Unabated by the criticism, SpaceX pressed ahead to prove its technology during actual flights. Whether it can succeed in its business model making profits is still a question, although a numbers game. The real success of SpaceX, however, is in its compulsion of rival launch service providers to think and make serious attempts at adopting reusability.

Tory Bruno, chief executive of ULA, admits that SpaceX had brought back the excitement to the space sector. ${ }^{66}$ It led ULA assess its cost structures, and reduce supply chain costs by $36 \%$. Airbus admits that its effort to design reusable systems has been stimulated by SpaceX. ${ }^{37}$ Adeline essentially is an idea to solve the performance penalty problem with Falcon 9. ISRO's officials refer to SpaceX when talking about reusability and their position in the commercial launch market even as China's scientists agree that making rockets reusable takes time and determination citing Musk. ${ }^{67}$ Shotwell contends that the industry has finally come around to embrace reusable launch vehicles in a manner described by Arthur C. Clarke. ${ }^{16}$ He had realized that there are 3 levels of reactions to a revolutionary idea-impossible to possible but not worth doing to final acceptance. This embrace is not just about adopting a new technology or a business model but also an industry-wide disruption leading to innovation and new inventions that could open outer space to businesses like never before.

However, Lt. Col. Tommy Schilling who worked with the USAF on innovative designs for reaching outer space had observed that competition is essential for unfolding reusable launch vehicles as the new paradigm. ${ }^{23}$ Indeed, Blue Origin and Virgin Galactic are just 2 other companies offering such launch services for accessing space. However, Jeff Bezos, founder of Blue Origin and Amazon, comments that this competition should not be cutthroat to determine future monopoly on commercial launch business, but creating an ecosystem for other entrepreneurs to thrive upon. ${ }^{68} \mathrm{Com}$ mercial satellite operators could be the first users to see the benefits accruing from these initiatives. SES had taken the bold step of launching its satellite on SpaceX's first attempt to reuse the core stage. It is already the biggest customer of SpaceX taking advantage of low-cost launches. Although SES had expected 50\% reduction in the launch cost, it was able to gain only $10 \% .^{35}$

SpaceX could be offering better discounts as it consolidates the mechanical and financial processes involved. The benefits offered by SpaceX are generally palpable despite not having proper figures at hand, particularly when the USAF also is seriously considering flying on reusable rockets. ${ }^{69}$ The service is interested in saving its costs but as far as SpaceX is concerned, it is not about merely justifying numbers, as opined earlier. It is the ability to take risk and determination to "shake up" the prevalent culture for building a better future. Legendary flight director Gene Kranz praises Musk for reigniting such spirit in the space industry, which also guided NASA in the 1960s and 1970s that made Apollo a reality. ${ }^{70} \mathrm{Kranz}$ admits that NASA has now succumbed to a large bureaucracy and cultural requirements that retards it. Apollo astronaut James McDivitt had put it more succinctly as he says the difference between NASA then and now is the parking lots at night. ${ }^{71}$ Such recognition is ideal for boosting the morale of SpaceX. After all, innovation is the key to maintaining the 
lead in any business. One of the business rivals, Airbus, understands this pattern and is considering being open to even accepting ideas and adopting innovations from outside the firm. ${ }^{72}$

\section{CONCLUSION}

Launch service providers across the world followed the same pattern of expending launch vehicles. SpaceX's proposition to make the rockets reusable was deemed absurd because of the earlier experiences with reusable systems. Although Russia had failed to lift off its program, the United States did not achieve the required flight rate that could have made space shuttles cheaper. However, both the government and commercial launch vehicle operators have now turned to reusability to survive the price competition unleashed by SpaceX.

SpaceX was able to survive many odds against it and had acquired a position influencing its rival companies to adopt its ideas. Different experiments are currently underway across the world that aimed at retrieving an entire stage of a rocket or critical components inside it. Analysis of ULA, Arianespace, India, and China programs reveals this trend. SpaceX figures prominently in the discussions on the future of these programs even as Elon Musk garnered global public appreciation for his determination to challenge the status quo. The disruption SpaceX had caused in the launch service industry could lead to 2020s becoming the decade of reusable launch systems offering low-cost access to space. This helps create a space-based economy transforming businesses on Earth with manufacturing moving into outer space, utilizing resources mined from the celestial bodies. For Musk, it is not about just creating a new economy but helping humanity itself survive by making Mars habitable.

Therefore, it is essential to assess the worth and success of SpaceX from a broader perspective of these future goals and vision rather than restrict it to mere finances.

\section{AUTHOR DISCLOSURE STATEMENT}

No competing financial interests exist.

\section{REFERENCES}

1. Pinchefsky C. 5 Horrifying Facts You Didn't Know About the Space Shuttle. Forbes. April 18, 2012. https://www.forbes.com/sites/carolpinchefsky/2012/04/ 18/5-horrifying-facts-you-didnt-know-about-the-space-shuttle/\#5a041c71f9d4 (Last accessed on April 23, 2017).

2. Pielke R, Byerly R. Shuttle programme lifetime cost. Nature. 2011;472(7341):38.

3. Watson T, Beiser D. NASA Chief Says Space Shuttle a Mistake for US. USA Today. September 27, 2005. https://usatoday30.usatoday.com/tech/science/ space/2005-09-27-nasa-griffin-interview_x.htm (Last accessed on April 24, 2017).
4. Berger E. Technical troubles likely to delay commercial crew flights until 2019. Ars Technica. January 27, 2017. https://arstechnica.com/science/2017/01/ sources-neither-boeing-nor-spacex-likely-ready-to-fly-crews-until-2019 (Last accessed on April 23, 2017).

5. Mosher D. Russia is squeezing NASA for more than $\$ 3.3$ billion-And there's little anyone can do about it. Business Insider. September 2, 2016. www.businessinsider.in/Russia-is-squeezing-NASA-for-more-than-3-3-billionand-theres-little-anyone-can-do-about-it/articleshow/53985221.cms (Last accessed on April 26, 2017).

6. Harwood W. Manned commercial flights to space station on track for 2017. CBS News. January 26, 2015. www.cosnews.com/news/manned-commercialflights-to-international-space-station-on-track-for-2017 (Last accessed on April 26, 2017).

7. Dillow C. Elon Musk is rushing to beat NASA to Mars, perhaps during Trump presidency. CNBC. May 17, 2017. www.cnbc.com/2017/05/17/elon-musk-isrushing-to-beat-nasa-to-mars-perhaps-during-trump-presidency.html (Last accessed on June 2, 2017).

8. Gilbert B. Reusable rockets are the key to interplanetary travel, according to Elon Musk. Business Insider India. September 11, 2015. www.businessinsider.in/ Reusable-rockets-are-the-key-to-interplanetary-travel-according-to-Elon-Musk/ articleshow/48906196.cms (Last accessed on April 29, 2017).

9. Falcon 9. SpaceX. www.spacex.com/falcon9 (Last accessed on April 29, 2017).

10. Foust J. Static fire test brings Falcon Heavy one step closer to debut. Space News. May 9, 2017. http://spacenews.com/static-fire-test-brings-falcon-heavyone-step-closer-to-debut (Last accessed on May 11, 2017).

11. Morris D. SpaceX Co-Founder Tom Mueller: We're Making the Competition 'Obsolete'. Fortune. May 14, 2017. http://fortune.com/2017/05/14/spacex-tommueller (Last accessed on May 21, 2017).

12. Reusability: The Key to Making Human Life Multi-Planetary. SpaceX. www .spacex.com/news/2013/03/31/reusability-key-making-human-life-multi-planetary (Last accessed on May 2, 2017).

13. Wattles J. SpaceX makes history: It launched a used rocket and then landed it in the ocean. CNN. March 31, 2017. http://money.cnn.com/2017/03/30/ technology/spacex-launch-ses-10-reused-rocket/index.html (Last accessed on May 5, 2017).

14. Harwood W. SpaceX successfully launches 2 nd rocket in 3 days. CBS News. October 11, 2017. https://www.cbsnews.com/news/spacex-launch-falcon-9rocket-communications-satellite (Last accessed on October 24, 2017).

15. Klotz I. SpaceX successfully launches first recycled rocket booster. Reuters. March 31, 2017. http://uk.reuters.com/article/us-space-spacex-launchidUKKBN1711JY (Last accessed on May 5, 2017).

16. Foust J. SpaceX gaining substantial cost savings from reused Falcon 9. Space News. April 5, 2017. http://spacenews.com/spacex-gaining-substantial-costsavings-from-reused-falcon-9 (Last accessed on May 5, 2017).

17. Wall M. SpaceX Rocket Could Be 100-Percent Reusable by 2018, Elon Musk Says. Space.com. April 10, 2017. https://www.space.com/36412-spacexcompletely-reusable-rocket-elon-musk.html (Last accessed on May 6, 2017).

18. Clark S. Musk wants to make Falcon rockets fully reusable. Spaceflight Now. April 11, 2017. https://spaceflightnow.com/2017/04/11/musk-wants-to-makefalcon-9-rocket-fully-reusable (Last accessed on May 9, 2017).

19. Selding P. SpaceX's reusable Falcon 9: What are the real cost savings for customers? Space News. April 25, 2016. http://spacenews.com/spacexsreusable-falcon-9-what-are-the-real-cost-savings-for-customers (Last accessed on May 7, 2017).

20. Berger E. Air Force budget reveals how much SpaceX undercuts launch prices. Ars Technica. June 16, 2017. https://arstechnica.com/science/2017/06/air-forcebudget-reveals-how-much-spacex-undercuts-launch-prices (Last accessed June on 21, 2017).

21. Davenport C. Elon Musk's SpaceX settles lawsuit against Air Force. The Washington Post. January 23, 2015. https://www.washingtonpost.com/business/ economy/elon-musks-spacex-to-drop-lawsuit-against-air-force/2015/01/23/ c5e8ff80-a34c-1 1e4-9f89-561284a573f8_story.html?utm_term=.253b2668ecd5 (Last accessed on May 8, 2017). 
22. Vincent J. ULA executive resigns after comments about SpaceX and 'fiancée' partners. The Verge. March 17, 2016. https://www.theverge.com/2016/3/17/ 11252926/ula-executive-resigns-after (Last accessed on May 8, 2017).

23. Waters R. United Launch Alliance chief plays down reusable rockets. Financial Times. April 6, 2017. https://www.ft.com/content/78d8b22e-1a39-11e7-bcac6d03d067f81f (Last accessed on May 9, 2017).

24. Kremer K. Genesis of ULA's New Vulcan Rocket Borne of Fierce Commercial and Political Pressures: Interview. Universe Today. December 23, 2015. https:// www.universetoday.com/119831/genesis-of-ulas-new-vulcan-rocket-borne-offierce-commercial-and-political-pressures-interview (Last accessed on May 10, 2017).

25. Ray J. ULA chief explains reusability and innovation of new rocket. Spaceflight Now. April 14, 2015. https://spaceflightnow.com/2015/04/14/ula-chiefexplains-reusability-and-innovation-of-new-rocket (Last accessed on May 11, 2017).

26. Ray J. ULA unveils its future with the Vulcan rocket family. Spaceflight Now. April 13, 2015. https://spaceflightnow.com/2015/04/13/ula-unveils-its-futurewith-the-vulcan-rocket-family (Last accessed on May 11, 2017).

27. Drew J. ULA and SpaceX on different paths toward rocket reuse. FlightGlobal. April 13, 2016. https://www.flightglobal.com/news/articles/ula-and-spacex-ondifferent-paths-toward-rocket-reus-424172 (Last accessed on May 11, 2017).

28. Arianespace marks its 2017 mid-year launch milestone with a record-setting Ariane 5 mission at the service of ViaSat and Eutelsat. ArianeSpace. June 1, 2017. www.arianespace.com/mission-update/arianespace-marks-its-2017-midyear-launch-milestone-with-a-record-setting-ariane-5-mission-at-theservice-of-viasat-and-eutelsat (Last accessed on June 15, 2017).

29. Astorg JM, Barreau F. The Ariane-5 Booster Recovery System. European Space Agency. February 1996. www.esa.int/esapub/bulletin/bullet85/gig085.htm (Last accessed on May 13, 2017).

30. Buursink J. Launch cost reduction by the reuse of the core stage of Ariane 5 Journal of Reducing Space Mission Cost. 1998;1(3):209-23.

31. Waldron G. Arianespace aims high in Asia-Pacific. FlightGlobal. June 1, 2016 https://www.flightglobal.com/news/articles/arianespace-aims-high-in-asia-pacific425928 (Last accessed on May 14, 2017).

32. Foust J. Inmarsat shifts satellite from SpaceX to Arianespace. Space News, December 8, 2016. http://spacenews.com/inmarsat-shifts-satellite-fromspacex-to-arianespace (Last accessed on May 15, 2017).

33. Selding P. European Commission OK's Airbus Safran Launchers takeover of Arianespace. Space News. July 20, 2016. http://spacenews.com/europeancommission-oks-airbus-safran-launchers-takeover-of-arianespace (Last accessed on May 16, 2017).

34. Clark S. OEtA with Stéphane Israël, chairman and CEO of Arianespace. Spaceflight Now. December 16, 2015. https://spaceflightnow.com/2015/12/16/ qa-with-stephane-israel-chairman-and-ceo-of-arianespace (Last accessed on May 17, 2017).

35. Wood C. Recycle, reuse: How cheap can SpaceX make space? Christian Science Monitor. February 4, 2017. https://www.csmonitor.com/Science/Spacebound/ 2017/0204/Recycle-reuse-How-cheap-can-SpaceX-make-space (Last accessed on May 19, 2017).

36. Selding P. With Eye on SpaceX, CNES Begins Work on Reusable Rocket Stage. Space News. January 5, 2015. http://spacenews.com/with-eye-on-spacex-cnesbegins-work-on-reusable-rocket-stage (Last accessed on May 19, 2017).

37. Selding P. Meet Adeline, Airbus' Answer To SpaceX Reusability. Space News. June 5, 2015. http://spacenews.com/meet-adeline-airbus-response-to-reusablespacex-rocket (Last accessed on May 20, 2017).

38. Bergin C. Airbus Safran promotes launch record ahead of Ariane 6 entering production. NASA Spaceflight. January 23, 2017. https://www.nasaspaceflight .com/2017/01/airbus-safran-ariane-5s-record-ariane-6-production (Last accessed on May 22, 2017).

39. Henry C. ESA kickstarts Prometheus reusable engine with first funding tranche. Space News. June 22, 2017. http://spacenews.com/esa-kickstarts-prometheusreusable-engine-with-first-funding-tranche (Last accessed on June 24, 2017).
40. Hollaway J. Has the space launch industry been too focused in the last 70 years? The Space Review. April 3, 2017. www.thespacereview.com/article/3209/ 1 (Last accessed on May 24, 2017).

41. Henry C. OneWeb breaks ground on a Florida factory that will build thousands of satellites. Space News. March 16, 2017. http://spacenews.com/onewebbreaks-ground-on-a-florida-factory-that-will-build-thousands-of-satellites (Last accessed on May 25, 2017).

42. Selding P. Launch Options were Key to Arianespace's OneWeb Win. Space News. June 26, 2015. http://spacenews.com/launch-options-were-key-to-arianespacesoneweb-win (Last accessed on June 10, 2017).

43. Brodkin J. With latency as low as $25 \mathrm{~ms}$, SpaceX to launch broadband satellites in 2019. Ars Technica. May 3, 2017. https://arstechnica.com/informationtechnology/2017/05/spacexs-falcon-9-rocket-will-launch-thousands-of-broadbandsatellites (Last accessed on June 12, 2017).

44. International Customer Satellites Launched. Antrix (ISRO). www.antrix.co.in/ business/international-customer-satellites-launched (Last accessed on June 12, 2017).

45. Private US firms oppose ISRO launching US satellites. Times of India. April 21, 2016. http://timesofindia.indiatimes.com/world/us/Private-US-firms-opposeISR0-launching-US-satellites/articleshow/51921599.cms (Last accessed on June 13, 2017).

46. Polar Satellite Launch Vehicle. Indian Space Research Organization. www.isro .gov.in/launchers/pslv (Last accessed on June 5, 2017).

47. Mehta I. ISRO's Satellite Success Story Has Only Just Begun. Huffington Post. February 17, 2017. www.huffingtonpost.in/2017/02/17/with-deals-of-400crores-in-the-bag-isro-wants-to-expand-the-sa_a_21716126 (Last accessed on May 29, 2017)

48. Selding P. U.S. launch companies lobby to maintain ban on use of Indian rockets. Space News. March 29, 2016. http://spacenews.com/u-s-spacetransport-companies-lobby-to-maintain-ban-on-use-of-indian-rockets (Last accessed on May 30, 2017).

49. Madhumathi DS. Global interest in PSLV soars. The Hindu. April 12, 2017. www.thehindu.com/sci-tech/science/global-interest-in-pslv-soars/article17958583 .ece (Last accessed on June 4, 2017).

50. Reusable Launch Vehicle-Technology Demonstration Program (RLV-TD). Indian Space Research Organization. www.isro.gov.in/technology-developmentprogrammes/reusable-launch-vehicle-technology-demonstration-program-rlvtd (Last accessed on June 4, 2017).

51. RLV-TD. Indian Space Research Organization. www.isro.gov.in/launcher/rlv-td (Last accessed on June 5, 2017).

52. Raj G. After Successful Test of Reusable Vehicle, ISRO Has Further Plans for Slashing Launch Costs. The Wire. May 23, 2016. https://thewire.in/37943/notjust-the-rlv-td-isro-has-more-plans-for-slashing-launch-costs (Last accessed on June 2, 2017).

53. Subramanian TS, Ramachandran R. Interview with Dr A.S. Kiran Kumar, Chairman, Indian Space Research Organisation. Frontline. June 24, 2016. www.frontline.in/science-and-technology/design-process-has-been-validated/ article8704727.ece (Last accessed on June 7, 2017).

54. ISRO all set to launch India's first space shuttle, RLV-TD: 10 facts you should know. India Today. May 16, 2016. http://indiatoday.intoday.in/education/story/ isro-all-set-to-launch-indias-first-space-shuttle-rlv-td-10-facts-you-shouldknow/1/669216.html (Last accessed on June 9, 2017).

55. France-India Space Cooperation-Agreements Signed on Future Launchers and Lunar Exploration. Centre national d'études spatiales (French Space Agency). January 9, 2017. https://presse.cnes.fr/en/france-india-space-cooperationagreements-signed-future-launchers-and-lunar-exploration (Last accessed on June 8,2017$)$.

56. International Customer for DFH-4 Satellite In-Orbit Delivery. China Great Wall Industry Corporation. www.cgwic.com/CommunicationsSatellite/customer.html (Last accessed on June 10, 2017).

57. Kuaizhou-1A Rocket Launches First Chinese Commercial Mission. News18. January 9, 2017. www.news18.com/news/tech/kuaizhou-1a-rocket-launchesfirst-chinese-commercial-mission-1333442.html (Last accessed on June 10, 2017). 


\section{REDDY}

58. Selding P. With Naga-L Rocket, China Would Turn Tables on U.S. Export Ban. Space News. October 15, 2015. http://spacenews.com/with-naga-l-rocketchina-would-turn-tables-on-u-s-export-ban (Last accessed on June 10, 2017).

59. Full text of white paper on China's space activities in 2016. The State Council, The People's Republic of China. December 28, 2016. http://english.gov.cn/ archive/white_paper/2016/12/28/content_281475527159496.htm (Last accessed on June 11, 2017).

60. Perrett B. CASC Aims For Reusability With Methane-Fuel Rocket Engine. Aviation Week. November 7, 2016. http://aviationweek.com/zhuhai-2016/cascaims-reusability-methane-fuel-rocket-engine (Last accessed on June 12, 2017).

61. Shumei L. New company set up to develop space economy. Global Times. October 21, 2016. www.globaltimes.cn/content/1012793.shtml (Last accessed on June 12,2017$)$.

62. Chen S. A new SpaceX? China developing system to recover, reuse space rockets. South China Morning Post. March 17, 2017. www.scmp.com/news/ china/policies-politics/article/2079822/new-spacex-china-developing-systemrecover-reuse-space (Last accessed on June 12, 2017).

63. David L. China's Mystery Space Plane Project Stirs Up Questions. Space.com. November 9, 2012. https://www.space.com/18410-china-space-plane-projectmystery.html (Last accessed on June 13, 2017).

64. Cantrell J. Why did Elon Musk ask Jim Cantrell and Adeo Ressi, in particular, to travel to Russia with him in 2001? Quora. November 26, 2015. https:// www.quora.com/Why-did-Elon-Musk-ask-Jim-Cantrell-and-Adeo-Ressi-inparticular-to-travel-to-Russia-with-him-in-2001 (Last accessed on June 13, 2017).

65. Wood C. Recycle, reuse: How cheap can SpaceX make space? Christian Science Monitor. February 4, 2017. https://www.csmonitor.com/Science/Spacebound/ 2017/0204/Recycle-reuse-How-cheap-can-SpaceX-make-space (Last accessed on June 14, 2017).

66. Thompson L. CEO Tory Bruno Explains How United Launch Alliance Will Stay Ahead Of Competitors. Forbes. October 14, 2016. https://www.forbes.com/sites/ lorenthompson/2016/10/14/ceo-tory-bruno-explains-how-united-launchalliance-will-stay-ahead-of-competitors/\#68f200764f6d (Last accessed on June 14, 2017)
67. China testing own reusable rocket technologies. Xinhua. April 21, 2016. http:// news.xinhuanet.com/english/2016-04/21/c_135300443.htm (Last accessed on June 10, 2017).

68. Boyle A. Interview: Jeff Bezos lays out Blue Origin's space vision, from tourism to off-planet heavy industry. Geek Wire. April 23, 2016. https://www.geekwire.com/ 2016/interview-jeff-bezos (Last accessed on June 14, 2017).

69. Klotz I. Air Force space chief open to flying on recycled SpaceX rockets. Reuters. April 6, 2017. www.reuters.com/article/us-space-spacex-military-idUSKBN1782ZS (Last accessed on June 15, 2017).

70. Berger E. Legendary flight director praises SpaceX for "taking risks." Ars Technica. April 13, 2017. https://arstechnica.com/science/2017/04/legendaryflight-director-praises-spacex-for-taking-risks (Last accessed on May 27, 2017).

71. Messier D. SpaceX's Strategy: Recruit the Best, Keep the Parking Lots Full at Night. Parabolic Arc. August 16, 2010. www.parabolicarc.com/2010/08/16/ spacexs-strategy-recruit-parking-lots-full-night (Last accessed on May 26, 2017).

72. Chowdhury A. In a first, Bengaluru startups on Airbus radar for mentoring business ideas under BizLabs. Economic Times. June 3, 2015. http://economictimes indiatimes.com/small-biz/startups/in-a-first-bengaluru-startups-on-airbus-radarfor-mentoring-business-ideas-under-bizlabs/articleshow/47507116 (Last accessed on June 10,2017$)$.

Address correspondence to: Vidya Sagar Reddy Nuclear and Space Policy Initiative Observer Research Foundation 20, Rouse Avenue, Institutional Area New Delhi 110002 India

E-mail: vidyasagar.reddy@orfonline.org; avs.sagar@gmail.com 